\title{
Modeling the Volatility of US Dollar/Albanian Lekë Exchange Rate
}

\author{
Rozana Liko*, Artion Kashuri \\ Department of Mathematics, University “Ismail Qemali”, Albania
}

Copyright $\bigcirc 2016$ by authors, all rights reserved. Authors agree that this article remains permanently open access under the terms of the Creative Commons Attribution License 4.0 International License

\begin{abstract}
The aim of this paper is to investigate the volatility of USD/ALL daily exchange rate using generalized autoregressive conditional heteroscedasticity model. The data set used in this study cover a period from 5 January 2010 to 30 April 2015. Autoregressive conditional heteroscedasticity (ARCH), generalized autoregressive conditional heteroscedasticity (GARCH), threshold generalized autoregressive conditional heteroscedasticity (TGARCH), and exponential GARCH (EGARCH) model are applied to model the volatility of daily exchange rate return. The main result is that volatility of exchange rate return is affected by past volatility, and exchange return of USD/ALL is well modeled by this model.
\end{abstract}

Keywords Exchange Rate, Volatility, ARCH, GARCH, EGARCH, TGARCH

\section{Introduction}

Modeling exchange rate volatility has gained a great importance and a number of models have been developed in empirical finance literature to investigate the volatility of exchange rate in different countries. Modeling and forecasting the exchange rate volatility is a crucial area for research because the foreign exchange volatility is an important determinant for pricing of currency derivative. Exchange rate volatility is a measure of the fluctuation in an exchange rate, and it is also known as a measure of risk [1]. The volatility of exchange rates is the source of exchange rates risk. Volatility has some commonly characteristics observed. First, high volatility is follows by high volatility and low volatility follows by low volatility, i.e. volatility acts in clusters. Second volatility often is stationary [2]. One such a models is the autoregressive conditional heteroscedasticity model (ARCH) introduced by Engle (1982). This model is generalized by Bollerslev (1986) into GARCH models. Nelson (1991) proposes the exponential GARCH (EGARCH) model which allow for asymmetric effect between positive and negative asset returns. Another model which allow for asymmetric is the threshold GARCH model (TGARCH). This model allows having differential impacts on conditional variance of the past shocks.

\section{Literature Review}

Since the adoption of the floating exchange rate regime the behavior of exchange rate has been investigated by many researches. F. X. Diebold and M. Nerlove (1989) investigated the volatility in seven nominal dollar spot exchange rate and showed strong evidence of ARCH effects, which capture volatility clustering, and factor structure capture commons volatility movements across exchange rates [3]. D. A. Hsieh (1989) investigates daily closing bid prices of foreign currencies in terms of US dollar, from January 1974 to December 1983. GARCH models with normal and no normal conditional distributions are estimated and the results showed that $\operatorname{GARCH}(1,1)$ model best described the conditional volatility for most nonlinearity data [4]. C.W. Chong, L. S. Chun and M. I. Ahmad (2002) used the GARCH models for estimated the volatility of exchange rate. The results of the volatility of RM/Sterling exchange rate at within sample suggest that long memory GARCH model performs better that the short-terms models in out-of-sample ARCH model and GARCH-M model outperforms others models in out-of-sample forecasting [5]. S. Voon and K. S. Lee (2008) studded the volatility of daily exchange rate Won/Dollar and finds that the past volatility of the exchange rate has persistency at the present [6]. A. Clement and A. Samuel (2011) examined the volatility of Naio/USD and Nairo/Uk pound Sterling using GARCH model, and they found that the return is persistent and that the variance equations are well specified in the GARCH model, during the period 2007-2011 [7]. Md. Z. Alan and Md. A. Rahman (2012) applied the GARCH type model to modeling the BDT/USD exchange rate using daily foreign exchange rate series and they found that in-sample both ARCH and ARMA models are the best models and out-of-sample the best model is GARCH model [8]. S. Rmzon et al. (2012) analyzed the monthly exchange rate of Pakistan from July 1981 to May 2010. They found that 
GARCH $(1,2)$ and EGARCH $(1,2)$ give the best prediction of exchange rates [9]. R. I. Gokbulut and M. Pekkay (2014) studding the conditional volatility of stock market, exchange rate and inters rate returns in Turkish financial market during the period from 2002 to 2014 and point out that the GARCH model show evidence of asymmetric effects in each market data and the asymmetric GARCH models performed better I forecasting the volatility of financial assets [10].

\section{Materials and Methods}

\subsection{Data}

The data consist of daily nominal exchange rate of US Dollar (USD) against Albanian Lekë (ALL). The time series cover the period from January 2010 to April 2015, i.e. 1344 observations for variables. The data set are obtain from Bank of Albania (http://www.bankofalbania.org/), the monetary authority of Albania, which applies a free fluctuation regime, i.e. the currency is determined according to the foreign exchange markets. The return of the exchange rates is calculated as, $r_{t}=\ln \left(\frac{s_{t}}{s_{t-1}}\right)$, where $s_{t}$ the exchange is rate at time moment $\mathrm{t}$.

\subsection{Methodology}

\subsubsection{Unit Root Test}

In order to check for stationarity we use Augmented Dicker Fuller (ADF) test and Philip-Perrons (PP) test. The null hypothesis of ADF test is the existence of unit root against the alternative hypothesis of no unit root. The null hypothesis is rejected if the test statistic is greater than the critical value. The PP test is similar to the ADF test, but correct for any serial correlation and heteroscedasticity in the errors terms. The null hypothesis of PP test is rejected if the test statistic is greater than the critical value.

\subsubsection{Test of Heteroscedasticity}

In order to apply the GARCH model first we examine the residual of the mean equation for heteroscedasticity, known as ARCH effects, by using ARCH-LM test. The ARCH-LM test is used to test the presence of conditional heteroscedasticity by regressed the squared residual on q lag. The null hypothesis of the test is no heteroscedasticity in the model residual versus the alternative hypothesis of heteroscedasticity in the model residual. The null hypothesis is rejected if the p-value is less that the significance level. Ljung-Box Q statistics test the joint hypothesis that the autocorrelation coefficients up to lag $\mathrm{q}$ are equal to zero on the squared residual series. The null hypothesis, that the autocorrelation function of the series is zero, is rejected if the $\mathrm{p}$-value of the test is less than the significance level.

\subsubsection{Modeling Volatility}

In ordinary last square estimation the variance of $\varepsilon_{t}$ is assumed to be constant. The autoregressive conditional heteroscedasticity $(\mathrm{ARCH})$ model violated this conditions assumed that the variance fluctuate on time. If $r_{t}$ is the exchange rate return series and $r_{\mathrm{t}}=\mu+\varepsilon_{\mathrm{t},}, \varepsilon_{\mathrm{t}}=\sigma_{\mathrm{t}} a_{\mathrm{t}}, a_{t}$ is a iid random variable and $a_{t} \sim N(0,1)$, then the $\mathrm{ARCH}(\mathrm{p})$ model is defined as follows,

$$
\sigma_{t}^{2}=\alpha_{0}+\alpha_{1} \varepsilon_{t-1}^{2}+\alpha_{2} \varepsilon_{t-2}^{2}+\cdots+\alpha_{p} \varepsilon_{t-p}^{2} .
$$

One weaknesses of ARCH model is that the model assumes that positive and negative shocks have the same effects on volatility. Bollerslev(1986) and Taylor(1986) developed the ARCH model into generalized autoregressive conditional heteroscedasticity (GARCH) model, which allow the conditional variance to depends not only by the squared residuals of mean equation but even by the previous own lags. The GARCH(p, q) model is

$$
\begin{gathered}
\varepsilon_{\mathrm{t}}=\sigma_{\mathrm{t}} a_{\mathrm{t}}, \quad \sigma_{\mathrm{t}}^{2}=\alpha_{0}+\sum_{\mathrm{i}=1}^{p} \alpha_{\mathrm{i}} \varepsilon_{\mathrm{t}-\mathrm{i}}^{2}+\sum_{i=1}^{q} \beta_{i} \sigma_{\mathrm{t}-\mathrm{i}}^{2}, \\
\alpha_{0}>0, \alpha_{\mathrm{i}} \geq 0, \beta_{\mathrm{i}} \geq 0 .
\end{gathered}
$$

Some weaknesses of GARCH model are the volatility clustering and tail distribution often is heavier than that of a normal distribution. To overcome weaknesses of GARCH Nelson (1991) proposes the EGARCH model. The $\operatorname{EGARCH}(\mathrm{p}, \mathrm{q})$ models is define as follows

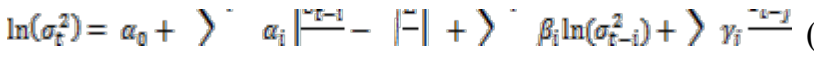

This model allowed capturing asymmetric effects of positive and negative shocks of the same magnitude.

A model commonly used to handle leverage effects is the Threshold GARCH (TGARCH) model proposed by Zakoian(1994). A TGARCH(p,q) model is as follows,

$$
\sigma_{t}^{2}=\alpha_{0}+\sum_{i=1}^{q}\left(\alpha_{i}+\gamma_{i} d_{t-i}\right) \varepsilon_{t-i}^{2}+\sum_{i=1}^{p} \beta_{i} \sigma_{t-i}^{2}
$$

where $d_{t-i}$ is an indicator for negative $\varepsilon_{t-\mathrm{i}}$.

\section{Results}

\subsection{Description Statistics of USD/ALL Series}

Table 1. Description statistics of USD/ALL

\begin{tabular}{|c|c|}
\hline Mean & 106.1512 \\
\hline Median & 105.0400 \\
\hline Maximum & 133.3500 \\
\hline Minimum & 95.21000 \\
\hline Std. Dev. & 6.504754 \\
\hline Skewness & 1.789083 \\
\hline Kurtosis & 7.357624 \\
\hline Jarque-Bera & 1780.361 \\
\hline Probability & 0.000000 \\
\hline
\end{tabular}

Table 1 shows some statistical descriptions of USD/ALL. As we can see the series is leptokurtic, kurtosis is highly 
positive 7.357 , and positively skewed with relative to normal distribution. Jarque-Bera test reject the null hypothesis of normality with $99 \%$ confidential interval (p-value lees that $0.01)$.

\subsection{Description Statistics of USD/ALL Returns Series}

Table 2 shows that the retuns series is leptokurtic, with kurtosis 5.028, and positively skewed. According to Jarque Bera statistic the return series has a non- normal distribution with $99 \%$ confidential interval, since p-value is less than 0.01 .

Table 2. Description statistics of USD/ALL returns

\begin{tabular}{|c|c|}
\hline Mean & 0.000203 \\
\hline Median & 0.000000 \\
\hline Maximum & 0.030837 \\
\hline Minimum & -0.022783 \\
\hline Std. Dev. & 0.005594 \\
\hline Skewness & 0.396356 \\
\hline Kurtosis & 5.028979 \\
\hline Jarque-Bera & 265.5305 \\
\hline Probability & 0.000000 \\
\hline
\end{tabular}

Figure 1 shows the volatility of USD exchange return. One can clearly observe that the stationarity and the volatility clustering of the return.

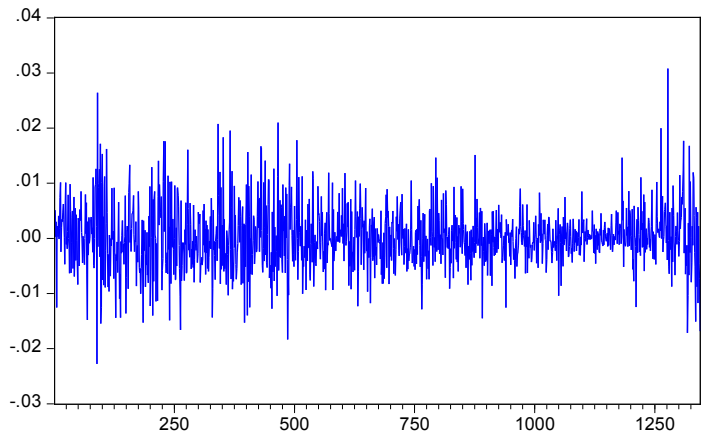

Figure 1. Graphic of USD return

Table 3. Unit root test of USD returns

\begin{tabular}{ccc}
\hline & $\begin{array}{c}\text { ADF } \\
\text { test statistic }\end{array}$ & $\begin{array}{c}\text { PP } \\
\text { test statistic }\end{array}$ \\
\hline t-Statistic & -36.14835 & -36.15007 \\
(Prob.*) $^{*}$ & 0.0000 & 0.0000 \\
\hline Test critical values: & -3.435012 & -3.435012 \\
$1 \%$ level & -2.863486 & -2.863486 \\
$5 \%$ level & -2.567855 & -2.567855 \\
$10 \%$ level &
\end{tabular}

Table 3 display the ADF test and PP test of unit root. The results indicate that according to both tests the series is stationary, since the value of ADF-test statistic and PP-test statistic is less that the critical value at significant level of $1 \%$.

\subsection{Modeling exchange Rate Return}

Table 4 display the result of heteroscedasticity of the residual of the USD return regressed on a constant. According to the ARCH test the null hypothesis for no ARCH effects is rejected with $99 \%$ confidential interval.

Table 4. Arch-LM test of USD returns regressed on a constant

\begin{tabular}{cccc} 
F-statistic & 23.8709 & Prob. F(1,1340) & 0.000 \\
Obs*R-squared & 23.4881 & Prob. Chi-Square(1) & 0.000 \\
\hline
\end{tabular}

Table 5 indicate the result of ARCH (1) estimation of USD return. The first part of the table displays the mean equation and the second part the variance equation. The variance equation shows that the squared residues are significant at $1 \%$ level.

Table 5. Estimation result of ARCH(1) model

\begin{tabular}{ccccc}
\hline Variable & Coefficient & Std. Error & z-Statistic & Prob. \\
\hline \multicolumn{5}{c}{ Mean Equation } \\
\hline$C$ & 0.000146 & 0.000146 & 1.000815 & 0.3169 \\
\hline \multicolumn{5}{c}{ Variance Equation } \\
RESID $(-1)^{\wedge} 2$ & 0.171761 & 0.035012 & 4.905810 & 0.0000 \\
\hline
\end{tabular}

Table 6 displays the result of GARCH $(1,1)$ model. In the variance equation the squared residual as well the GARCH(-1) coefficient are significant at $1 \%$ level. The sum of $\alpha+\beta<1$, which implied persistence of volatility in daily exchange rate.

Table 6. Estimation result of $\operatorname{GARCH}(1,1)$

\begin{tabular}{ccccc}
\hline Variable & Coefficient & $\begin{array}{c}\text { Std. } \\
\text { Error }\end{array}$ & Z-Statistic & Prob. \\
\hline \multicolumn{5}{c}{ Mean Equation } \\
\hline $\mathrm{C}$ & 0.000162 & 0.00013 & 1.213187 & 0.2251 \\
\hline $\mathrm{C}$ & Variance Equation \\
RESID $(-1)^{\wedge} 2$ & 0.034992 & 0.005320 & 6.577720 & 0.0000 \\
GARCH(-1) & 0.962195 & 0.005983 & 160.8148 & 0.0000 \\
\hline
\end{tabular}

Table 7. Estimation result of $\operatorname{EGARCH}(1,1)$ model

\begin{tabular}{ccccc}
\hline Variable & Coefficient & Std. Error & z-Statistic & Prob. \\
\hline \multicolumn{5}{c}{ Mean Equation } \\
\hline C & 0.000244 & 0.00013 & 1.806246 & 0.070 \\
\hline \multicolumn{5}{c}{ Variance Equation } \\
C(2) & -0.081716 & 0.02415 & 3.38369 & 0.000 \\
ABS(RESID(-1))/ & 0.049286 & 0.01097 & 4.49184 & 0.000 \\
SQRT(GARCH(-1)) & & & \\
RESID(-1)/ & 0.036083 & 0.00394 & 9.14454 & 0.000 \\
SQRT(GARCH(-1)) \\
Log(GARCH(-1)) & 0.995690 & 0.00172 & 577.335 & 0.000 \\
\hline
\end{tabular}

As can be viewed from the variance equation of table 7, all the coefficients are significant at $1 \%$ level. The sum of ? and ? approximately to 1 revel persistence in volatility. 
Positivity of asymmetric coefficient indicates that the positive shocks increase volatility more that negative shocks. So the leverage effects are not supported by our data.

TGARCH $(1,1)$ estimation, table 8 , shows that all coefficients are significant at $1 \%$ level, except the constant in the mean equation. The asymmetric coefficient in TGARCH model is less than zero implied that good news increase volatility more that bad news.

Table 8. Estimation result of $\operatorname{TGARCH}(1,1)$ model

\begin{tabular}{|c|c|c|c|c|}
\hline Variable & Coefficient & Std. Error & z-Statistic & Prob. \\
\hline \multicolumn{5}{|c|}{ Mean Equation } \\
\hline C & 0.000217 & 0.000134 & 1.624581 & 0.104 \\
\hline \multicolumn{5}{|c|}{ Variance Equation } \\
\hline C & $6.72 \mathrm{E}-08$ & $2.59 \mathrm{E}-08$ & 2.593402 & 0.009 \\
\hline RESID(-1)^2 & 0.036929 & 0.004524 & 8.162932 & 0.000 \\
\hline $\begin{array}{c}\text { RESID(-1)^ }{ }^{*}(\text { RESID }(-1) \\
0)\end{array}$ & -0.026623 & 0.005091 & -5.229883 & 0.000 \\
\hline GARCH(-1) & 0.974282 & 0.004573 & 213.0721 & 0.000 \\
\hline
\end{tabular}

According to the AIC and SIC criteria, display in table 9, the best model is the $\operatorname{EGARCH}(1,1)$ model. The Ljung-Box statistics of the standardized residuals, Q(12), confirms that the mean equation of all the models are adequate, all p-values are greater than 5\%. Moreover the Ljung-Box of the squared standardized residual, , indicates that the standardized residuals have no conditional heteroscedasticity, so the variance equations are adequate. Jarque- Bera statistic strongly rejects the normal distribution of the standardized residual, with p-value less than 0.01 .

Table 9. Estimation model

\begin{tabular}{|c|c|c|c|c|}
\hline & ARCH(1) & $\begin{array}{c}\text { GARCH } \\
(1,1)\end{array}$ & $\begin{array}{c}\text { EGARH } \\
(1,1)\end{array}$ & $\begin{array}{c}\text { TGRCH } \\
(1,1)\end{array}$ \\
\hline AIC & -7.55761 & -7.6712 & $\mathbf{- 7 . 6 7 8 4}$ & -7.675513 \\
\hline SIC & -7.54599 & -7.65573 & $\mathbf{- 7 . 6 5 9 1}$ & -7.65614 \\
\hline \multirow{2}{*}{ (12) } & 16.028 & & 12.874 & 12.952 \\
& $(0.19)$ & & $(0.37)$ & $(0.37)$ \\
\hline \multirow{2}{*}{$Q^{2}(12)$} & 73.372 & 6.606 & 8.228 & 7.189 \\
& $(0.00)$ & $(0.88)$ & $(0.76)$ & $(0.84)$ \\
\hline \multirow{2}{*}{ ARCH-LM } & 0.12819 & 0.00358 & 0.04374 & 0.14395 \\
& $(0.72)$ & $(0.95)$ & $(0.83)$ & $(0.70)$ \\
\hline Jarque-Bera & 245.67 & 434.35 & 289.03 & 338.96 \\
test & $(0.00)$ & $(0.00)$ & $(0.00)$ & $(0.00)$ \\
\hline
\end{tabular}

Note: Actual p-values are reported in breaks

\section{Conclusions}

In this paper we attempts to investigate the model of volatility of USD/ALL exchange rate return. The data set consists from 5 January 2010 to April 2015. Some autoregressive conditional heteroscedasticity models are employs, such as the $\operatorname{ARCH}(1), \operatorname{GARCH}(1,1)$,
TGARCH $(1,1)$ and $\operatorname{EGARCH}(1,1)$. The coefficients of the estimated model are all significant at $1 \%$ level, except for the constant in the mean equations. Since the GARCH(-1) coefficient of the $\operatorname{GARCH}(1,1)$ model is significant, this indicates that the past volatility influences the current volatility. The EGARCH model shows persistence in volatility and no leverage effects. In TGARCH model the asymmetric coefficient less than one indicate that good news increase volatility more that bad news. According to $\mathrm{ACI}$ and SCI criteria the EGARCH $(1,1)$ model is the most adequate model.

\section{REFERENCES}

[1] S. Z. S. Abdalla, Modelling Exchange Rate Volatility using GARCH Models: Empirical Evidence from Arab Countries, International Journal of Economics and Finance, Vol. 4, No. 3; 2012

[2] R. S. Tsay, Analysis of financial time series, third edition, John Wiley \& Sons, Inc., 2010.

[3] F. X. Diebold, M. Nerlove. The dynamics of exchange rate volatility: A multivariate latent Factor ARCH Model, Journal of Applied econometrics, Vol 4, 1-21, 1989

[4] D. A. Hsieh, Testing for nonlinear Dependence in Daily Foreign Exchange Rate, The Journal of Business, Vol. 62, No. 3: $339-368,1989$.

[5] C. W. Chong, L. S. Chun, M. I. Ahmad. Modelling the Volatility of Currency Exchange Rate Using GARCH Model, Pertanika J. Soc. Sci. \& Hum. Vol.10, No.2: 85-95, 2002, ISSN: 0128-7702.

[6] S. Yoon, K. S. Lee. The Volatility and Asymmetry of Won/Dollar Exchange Rate, Journal of Social Sciences, Vol. 4, No. 1: 7-9, 2008 ISSN 1549-3652

[7] A. Clement, A. Samuel. Empirical Modeling of Nigerian Exchange Rate Volatility, Mathematical Theory and Modeling, Vol.1, No.3, 2011, ISSN 2224-5804 (Paper) ISSN 2225-0522 (Online)

[8] Md. Z. Alam, Md. A. Rahman. Modelling Volatility of the BDT/USD Exchange Rate with GARCH Model, International Journal of Economics and Finance; Vol. 4, No. 11; 2012, ISSN 1916-971X E-ISSN 1916-9728

[9] S. Ramzan, S. Ramzan, F. M. Zahid. Modeling and forecasting exchange rate dynamics in Pakistan using arch family of models, Electronic Journal of Applied Statistical Analysis, Vol. 5, Issue 1: 15 - 29, 2012, E-ISSN 2070-5948

[10] R. İlker Gökbulut, Mehmet Pekkaya. Estimating and Forecasting Volatility of Financial Markets Using Asymmetric GARCH Models: An Application on Turkish Financial Markets, International Journal of Economics and Finance; Vol. 6, No. 4, 2014, ISSN 1916-971X, E-ISSN 1916-9728 